\title{
Hydrodynamic behaviour of velocity of applied magnetic field on unsteady MHD Couette flow of dusty fluid in an annulus
}

\author{
Basant K. Jha ${ }^{1, \mathrm{a}}{ }_{\mathbb{D}}$, Dauda Gambo ${ }^{2, \mathrm{~b}}{ }_{\mathbb{D}}$ \\ ${ }^{1}$ Department of Mathematics, Ahmadu Bello University, Zaria, Nigeria \\ 2 Department of Mathematics and Statistics, King Fahd University of Petroleum and Minerals, Dhahran, Saudi \\ Arabia
}

Received: 6 October 2021 / Accepted: 10 December 2021

(C) The Author(s) 2021

\begin{abstract}
This research work inspects mass transport phenomenon of Saffman's dusty fluid model for transient magnetohydrodynamics fluid flow of a binary mixture passing through an annular duct. Particularly, effort has been devoted to theoretically explore the role of velocity of applied magnetic field. Here, our treatment of the governing momentum equations accountable for the flow is done using the classical Laplace transform technique and RiemannSum Approximation. The effects of the physical parameters such as time, relaxation time parameter, radii ratio, Hartmann number, variable mass parameter and velocity of applied magnetic field on the fluid phase velocity, dust phase velocity and skin friction have been illustrated pictorially. It is concluded that contrary to the known classical effect of boosting Hartmann number on velocity, both components of flow (fluid and dust phase) and skin friction are seen to be heightened with an overwhelming presence of velocity of applied magnetic field. For large time, it is anticipated that higher profiles for velocity and skin friction are seen with fluid phase and an accelerated moving wall.
\end{abstract}

\section{List of symbols}

$\mathrm{B}_{0} \quad$ Magnetic flux $\left(\mathrm{Kg}^{-1} \mathrm{~s}^{-2} \mathrm{~A}^{-1}\right)$

Ha Hartmann number

J Current density $\left(\mathrm{Am}^{-2}\right)$

$\mathrm{K}$ Stokes resistance coefficient $\left(\mathrm{Kgs}^{-1}\right)$

$\mathrm{K}_{\mathrm{v}}^{\prime} \quad$ Dimensional velocity of applied magnetic field

$\mathrm{K}_{\mathrm{V}} \quad$ Dimensionless velocity of applied magnetic field

$\mathrm{m}$ Mass of dust particles $(\mathrm{Kg})$

$\mathrm{N}_{0} \quad$ Number density of dust particles

$\mathrm{r}^{\prime} \quad$ Dimensional radial distance $(\mathrm{m})$

$\mathrm{R}$ Dimensionless radial distance

$\mathrm{r}_{1} \quad$ Radius of inner cylinder $(\mathrm{m})$

$\mathrm{r}_{2}$ Radius of outer cylinder $(\mathrm{m})$

\footnotetext{
a e-mail: basant777@yahoo.co.uk

b e-mail: daudagambo85@gmail.com (corresponding author)
} 
s Laplace parameter

$\mathrm{t}^{\prime} \quad$ Dimensional time

$\mathrm{t}$ Dimensionless time (s)

$\mathrm{u}^{\prime}$ Dimensional fluid phase velocity

$\mathrm{U}_{0}$ Characteristic velocity

U Dimensionless fluid phase velocity

$v^{\prime}$ Dimensional dust phase velocity

V Dimensionless dust phase velocity

\section{Greek letters}

$\alpha$ Varying mass parameter of dust particle

$\beta$ Electrical conductivity $\left(\mathrm{Kg}^{-1} \mathrm{~m}^{-3} \mathrm{~s}^{3} \mathrm{~A}^{2}\right)$

$\rho$ Fluid density $\left(\mathrm{Kgm}^{-3}\right)$

$\sigma \quad$ Relaxation time parameter (s)

$\lambda$ Radii ratio $\left(\frac{\mathrm{r}_{2}}{\mathrm{r}_{1}}\right)$

$v$ Kinematic fluid viscosity $\left(\mathrm{m}^{2} \mathrm{~s}^{-1}\right)$

$\tau$ Skin friction

\section{Introduction}

Studies related to two-phase hydromagnetic fluid flow models have remained very active due to their increasing importance in the field of geophysics and engineering. Such flows help in better understanding several manufacturing and industrial processes, e.g. purification of crude oil, centrifugal separation of matter from fluid, fluidization, sedimentation, plasma studies, geothermal energy extraction, powder technology and paint spraying. Understanding the phenomenon of dusty fluid (fluid with a distribution of tiny dust particles) aids in improving the efficiency of such devices conveying the fluid. This can be achieved by overcoming the wear activities and viscous stresses produced by the resultant interaction of the dust particles in the form of sooth or ash suspended in the particulate suspension.

Saffman [1] initiated the study on the motion of fluid saturated with dusty particles and formulated the governing equation accountable for dusty fluid. Liu [2] examined the motion of a dusty gas driven by an oscillating infinite flat plate. The role of impulsive and accelerated motion of one of the bounding plates on Couette motion of a dusty gas has been analysed by Nag et al. [3]. Gupta [4] scrutinised the flow of a viscous incompressible and electrically conducting fluid in the region between two infinite parallel plates where the influence of external magnetic field is taken into consideration. The flow is assumed to be triggered by the impulsive motion of the bounding plate. In another related study, Rossow [5] investigated the role of impulsive and accelerated motion on hydromagnetic viscous flow in the presence of external magnetic field. The unsteady motion of a viscous and electrically conducting fluid suspended with dust gas in which the flow was triggered from rest by the sudden impulsive movement of the bounding plates was considered by Mitra and Bhattacharyya [6]. In their work, four different types of boundary movement were taken into account. The influence of ramped velocity on MHD free convective flow in a coaxial cylinder has been reported by Vanita and Kumar [7]. They concluded that the velocity of applied magnetic field is enhanced with an increase in radii ratio and skin friction is rendered ineffective with an increase in 
the velocity of magnetic field. Related literature in which several investigators have studied various flow configuration in a channel as well as annulus in which the flow sets in by either impulsive or accelerated movement of the wall can be found in references [8-10].

Regarding the ongoing investigation, Datta and Mishra [11] numerically examined the steady boundary layer flow of a two-phase fluid passing over a growing flat plate. Employing the finite difference method to solve the governing momentum and energy equations, Attia [12] analysed the effects of electric conductivity and variable viscosity on unsteady magnetohydrodynamic flow of a dusty fluid in a channel. Kumar and Singh [13] exhibited exact solution for hydromagnetic fluid flow in a channel with ramped velocity. They reported four cases of motion of magnetic field. On the other hand, Gireesha et al. [14] undertook an examination on boundary layer flow and thermal analysis of fluid suspended with dust particle with nonuniform heat source/sink passing over a stretching sheet. Later on, the effect of viscous dissipation and internal heat generation/absorption on the motion of a dusty fluid over an unsteady stretching sheet was presented numerically by Gireesha et al. [15]. In furtherance of this work, Gireesha et al. [16, 17] and Ramesh et al. [18, 19] have all presented details on the effects of thermal radiation and Hall effect on dusty fluid over stretching surfaces. One unique feature of their work is they employed a purely numerical approach in solving the governing equations.

However, despite the attempt made by previous workers both experimentally and theoretically to better understand the physics of the binary mixture and compelling evidence have been recorded about the behaviour of the fluid, there are still restrictions when it comes to deriving the exact analytical solution for the unsteady flows in macro-/micro-annular geometry of which its mathematical ingenuity cannot be overemphasised. This is due to the complexity arising from the nonlinear nature of the coupled system. However, several investigators have offered numerous numerical approaches to such flow phenomena for various geometries. In the light of this, we shall study references [20-29].

Advances in hydrodynamic and thermal attributes of electrically conducting and nonconducting viscous fluids in an unsteady flow have been reported by a lot of investigators for different models. The buoyancy effect on unsteady flow of heat generating/absorbing viscous fluid saturated with porous materials of uniform porosity was exhibited by Yusuf and Gambo $[30,31]$. Gambo and Gambo [32, 33] offered the steady MHD flow in an annulus with thermal source/sink and suction/injection respectively. To understand the effect of heat distribution on an electrically conducting heat generating/absorbing fluid for different homogeneous industrial fluids prescribed by their Prandtl value, Gambo et al. [34] scrutinised the flow in an annulus with adiabatic and isothermal condition. Several numerical and analytical approaches have been considered in the treatment of the highly nonlinear and constitutive couple equations for different models. Generally, the thermal distribution in the system is seen to properly accentuate the flow characteristics. Recently, Jha and Gambo $[35,36]$ have studied the hydrodynamics attribute of fluid passing through an annulus based on Dean flow.

The work of Jha and Gambo [37-39] and Yusuf et al. [40] had significantly reshaped the studies of transient flow formations in different geometries. In their work, they employed the use of the classical Laplace transformation in conjunction with Riemann-Sum Approximation (RSA) in treatment of nonlinear partial differential equations. This is attributed to the intricacy associated with the Laplace domain solution arising from the nonlinear nature of the controlling equations which makes the classical Laplace inversion method primitive and inadequate.

In the light of the survey carried out, we anticipated the semi-analytical study for the unsteady multiphase flow. To the best of authors' knowledge, no work has been done to specifically analyse the impact of velocity of applied magnetic field and relative boundary 
movement on an electrically conducting binary fluid. To fill in the gap, we set out to theoretically examine the motion of an electrically conducting dusty fluid in a horizontal annulus.

The purpose of this analysis is to study the effect of velocity of applied magnetic field and relative motion on magnetohydrodynamics fluid flow saturated with dust particles. Laplace transform techniques are applied in solving the nonlinear coupled partial differential equations for fluid and dust phase in Laplace domain. A numerical inverting technique known as Riemann-Sum Approximation (RSA) has been employed in transforming the Laplace domain solution to time domain. The Riemann-Sum Approximation (RSA) solution demonstrates excellent agreement when compared with the exact solution at large time. The influence of the flow parameters on the flow formation was studied in detail. This phenomenon is seen in cavitation pumps and turbines and biomedical equipment conveying heterogeneous mixtures.

\section{Mathematical formulation}

In the present study, the transient fully developed flow of a viscous incompressible and electrically conducting dusty fluid in an annular gap formed by two infinitely long horizontal coaxial cylinders was considered. Here, the polar coordinate system $\left(r^{\prime}, \theta, z^{\prime}\right)$ was suitably chosen such that the cylinders lie on the $z^{\prime}$-axis and the $r^{\prime}$-axis in the radial direction normal to the axis of the cylinder. Let $r_{1}$ and $r_{2}$ denote the radii of the inner and outer cylinder, respectively (See Fig. 1). We assumed that the dust particles are uniformly distributed in the fluid and spherical in shape. The perturbation of the magnetic Reynolds number as a result of the electric current flowing in the multi-phase fluid is taken to be small enough such that the influence of the induced magnetic field is negligible Pai [41]. Thus, a uniform magnetic field $\mathrm{B}_{0}$ is applied externally on the dusty fluid. The number density of dust particle $\left(N_{0}\right)$ is assumed to be constant throughout the motion, and the volume fraction of the dust particle is neglected. Initially, we assumed that at $t^{\prime} \leq 0$, the fluid, dust particles and the cylinders are at rest. At $t^{\prime}>0$, the motion is triggered by the sudden application of the external uniform magnetic field and movement of the outer cylinder moving with a velocity $U_{0} t^{\prime n}$ where $n$ is any positive integer and $U_{0}$ the characteristic velocity. In our analysis, we assumed two values of $n ; n=0$ to correspond to impulsive motion of the outer cylinder and $n=1$ to denote uniformly accelerated motion of the outer cylinder.

The modified Saffman's [1] equation for a conducting dusty fluid and non-conducting dusty fluid utilised in formulating the flow formation are:

$$
\begin{gathered}
\frac{\partial u^{\prime}}{\partial t^{\prime}}+\left(u^{\prime} \cdot \nabla\right) u^{\prime}=v^{\prime} \nabla^{2} u^{\prime}+\frac{K^{\prime} N_{0}}{\rho}\left(v^{\prime}-u^{\prime}\right)+\frac{1}{\rho}\left(J \times B_{0}\right), \\
m \cdot\left[\frac{\partial v^{\prime}}{\partial t^{\prime}}+\left(v^{\prime} \cdot \nabla\right) v^{\prime}\right]=K^{\prime}\left(u^{\prime}-v^{\prime}\right), \\
\operatorname{Div} u^{\prime}=0, \\
\frac{\partial N_{0}}{\partial t^{\prime}}+\operatorname{div}\left(N_{0} v^{\prime}\right)=0 .
\end{gathered}
$$

Using the above assumptions, the governing equation describing the fluid transport can be written following Saffman [1], Mitra and Bhattacharyya [6] and Jha and Apere [9] as:

$$
\begin{gathered}
\frac{\partial u^{\prime}}{\partial t^{\prime}}=v\left[\frac{\partial^{2} u^{\prime}}{\partial r^{\prime 2}}+\frac{1}{r^{\prime}} \frac{\partial u^{\prime}}{\partial r^{\prime}}\right]+\frac{K^{\prime} N_{0}}{\rho}\left(v^{\prime}-u^{\prime}\right)-\frac{\beta B_{0}^{2}}{\rho U_{0}}\left(u^{\prime}-K_{v}^{\prime} t^{\prime} n\right), \\
\mathrm{m} \cdot \frac{\partial \mathrm{v}^{\prime}}{\partial \mathrm{t}^{\prime}}=\mathrm{K}^{\prime}\left(\mathrm{u}^{\prime}-\mathrm{v}^{\prime}\right) .
\end{gathered}
$$




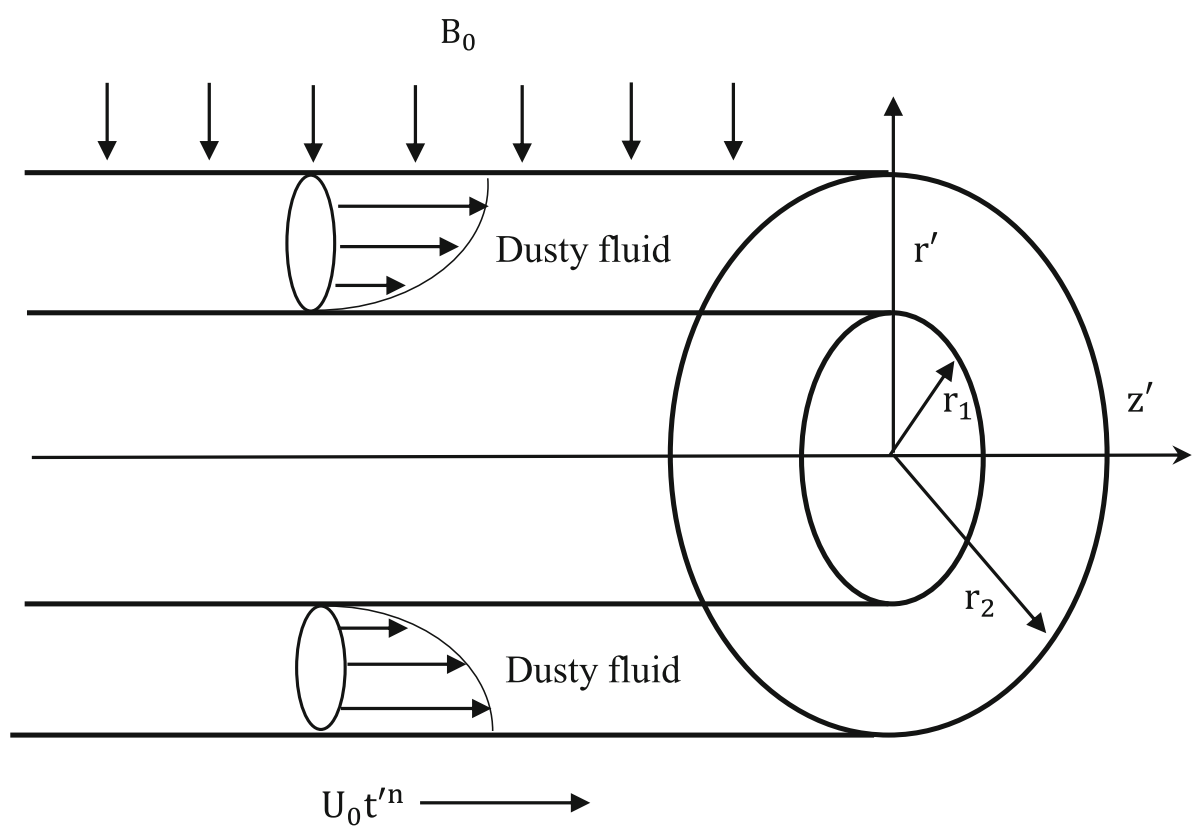

Fig. 1 Physical configuration and coordinate system of the problem

With the appropriate initial and boundary conditions.

For $t^{\prime} \leq 0, u^{\prime}=0, r_{1} \leq r^{\prime} \leq r_{2}$.

$$
\text { At } t^{\prime}>0\left\{\begin{array}{l}
u^{\prime}=0 \text { at } r^{\prime}=r_{1} \\
u^{\prime}=U_{0} t^{\prime n} \text { at } r^{\prime}=r_{2} .
\end{array}\right.
$$

The following non-dimensional parameters have been defined to transform Eqs. (5)-(7) into their respective dimensionless forms as defined by Mitra and Bhattacharyya [6], Vanita and Kumar [7] and Jha and Apere [9]:

$$
\begin{gathered}
t=\frac{v t^{\prime}}{r_{1}^{\prime 2}} ; \mathrm{Ha}=B_{0} r_{1}^{\prime}\left(\frac{\beta}{v \rho}\right)^{\frac{1}{2}} ; \lambda=\frac{r_{2}^{\prime}}{r_{1}^{\prime}} ; \quad V=\frac{v^{\prime}}{U_{0}} ; U=\frac{u^{\prime}}{U_{0}} ; \\
R=\frac{r^{\prime}}{r_{1}^{\prime}} ; \alpha=\frac{m N_{0}}{\rho} ; \sigma=\frac{m^{\prime}}{K^{\prime} r_{1}^{\prime 2}} ; K_{v}=\frac{K_{v}^{\prime}}{U_{0}} ;
\end{gathered}
$$

Thus Eqs. (5)-(7) reduce to

$$
\begin{gathered}
\frac{\partial U}{\partial t}=\frac{\partial^{2} U}{\partial R^{2}}+\frac{1}{R} \frac{\partial U}{\partial R}-\operatorname{Ha}^{2}\left(U-K_{v} t^{n}\right)+\frac{\alpha}{\sigma}(V-U) \\
\sigma \frac{\partial V}{\partial t}=(U-V) .
\end{gathered}
$$

Under the following initial and boundary conditions

$$
\begin{gathered}
t \leq 0 ; U=01 \leq R \leq \lambda, \\
\text { at } t>0\left\{\begin{array}{c}
U=0 \text { at } R=1 \\
U=t^{n} \text { at } R=\lambda,
\end{array}\right.
\end{gathered}
$$

where $K_{v}$ is the velocity of applied magnetic field. Here, four conditions of velocity of applied magnetic fields were considered: 
i. When the velocity of applied magnetic field is withdrawn $\left(K_{v}=0\right)$.

ii. When the velocity of applied magnetic field is less than the velocity of outer cylinder $\left(K_{v}=0.5\right)$.

iii. When the velocity of applied magnetic field equals the velocity of outer cylinder $\left(K_{v}=1.0\right)$.

iv. When the velocity of applied magnetic field is greater than the velocity of the outer cylinder $\left(K_{v}=1.5\right)$.

We proceed to obtain the solutions of (9) and (10) for the two cases: the impulsive motion of the outer cylinder $(n=0)$ and the accelerated motion of the outer cylinder $(n=1)$ for both fluid phase and dust phase. This is achieved by taking $n=0$ and $n=1$, respectively, in (9) and (11).

\subsection{Case I: impulsive motion}

By taking $n=0$ in Eqs. (9) and (11), Eqs. (9)-(11) are recast to simulate the impulsive motion of the outer cylinder and are given as:

$$
\begin{gathered}
\frac{\partial U}{\partial t}=\frac{\partial^{2} U}{\partial R^{2}}+\frac{1}{R} \frac{\partial U}{\partial R}-\mathrm{Ha}^{2}\left(U-K_{v}\right)+\frac{\alpha}{\sigma}(V-U), \\
\sigma \frac{\partial V}{\partial t}=(U-V), \\
t \leq 0 ; U=0 ; 1 \leq R \leq \lambda, \\
\text { at } \mathrm{t}>0\left\{\begin{array}{l}
U=0 \text { at } R=1 \\
U=1 \text { at } R=\lambda .
\end{array}\right.
\end{gathered}
$$

Seeing that Eqs. (12)-(14) are time dependent, we adopt the use of the Laplace transform technique in transforming Eqs. (12)-(14) to the Laplace domain. This is achieved by employing the Laplace transform defined by $\bar{f}(R, s)=\int_{0}^{\infty} f(R, t) e^{-s t} d t$ where s represents the Laplace parameter and $\mathrm{s}>0$.

Thus, Eqs. (12)-(14) in the Laplace domain are given as:

$$
\begin{gathered}
\frac{d^{2} \bar{U}}{d R^{2}}+\frac{1}{R} \frac{d \bar{U}}{d R}-\left(s+\mathrm{Ha}^{2}\right) \bar{U}+\frac{\mathrm{Ha}^{2} K_{v}}{s}+\frac{\alpha}{\sigma}(\bar{V}-\bar{U})=0, \\
s \sigma \bar{V}=\bar{U}-\bar{V},
\end{gathered}
$$

subject to

$$
\left\{\begin{array}{c}
\bar{U}=0 \text { at } R=1 \\
\bar{U}=\frac{1}{s} \text { at } R=\lambda .
\end{array}\right.
$$

Alternatively, Eq. (16) can be written as:

$$
\bar{V}-\bar{U}=\frac{-s \sigma}{1+s \sigma} \bar{U} .
$$

Substituting Eq. (18) into (15), we obtain

$$
\frac{d^{2} \bar{U}}{d R^{2}}+\frac{1}{R} \frac{d \bar{U}}{d R}-\left(s+\mathrm{Ha}^{2}+\frac{\alpha s}{1+s \sigma}\right) \bar{U}=-\frac{\mathrm{Ha}^{2} K}{s} .
$$

Following Jha and Apere [9], Jha and Gambo [37, 38] and Tsangaris et al. [42], the non-homogeneous linear differential equation in (19) can be reduced using the given transformation below:

$$
\bar{U}(R, s)=\bar{F}(R, s)+\frac{\mathrm{Ha}^{2} K_{v}}{s \delta^{2}},
$$


where $\overline{\mathrm{F}}(\mathrm{R}, \mathrm{s})$ is the homogenous solution of Eq. (19) and $\delta=\left(\mathrm{s}+\mathrm{Ha}^{2}+\frac{\alpha s}{1+s \sigma}\right)^{\frac{1}{2}}$.

Accordingly, under the modified boundary conditions in (17), the general solution of the fluid phase velocity in Eq. (19) is given as:

$$
\bar{U}(R, s)=A_{1} I_{0}(R \delta)+A_{2} K_{0}(R \delta)+\frac{\mathrm{Ha}^{2} K_{v}}{s \delta^{2}},
$$

where $\mathrm{I}_{0}$ and $\mathrm{K}_{0}$ are, respectively, the modified Bessel functions of the first kind and second kind and expressions for $\mathrm{A}_{1}$ and $\mathrm{A}_{2}$ are given in the "Appendix" section.

The drag on the surfaces of the cylinders otherwise known as skin friction produced by the resultant interaction between the fluid phase and the boundary is computed. The skin frictions on the surface of the inner and outer cylinder can be derived by directly differentiating Eq. (21) and evaluating at $R=1$ and $R=\lambda$, respectively.

$$
\begin{gathered}
\bar{\tau}_{1}(1, s)=\left.\frac{d}{d R} \bar{U}(1, s)\right|_{R=1}=\delta\left[A_{1} I_{1}(\delta)-A_{2} K_{1}(\delta)\right], \\
\bar{\tau}_{\lambda}(\lambda, s)=\left.\frac{d}{d R} \bar{U}(\lambda, s)\right|_{R=\lambda}=\delta\left[A_{1} I_{1}(\lambda \delta)-A_{2} K_{1}(\lambda \delta)\right] .
\end{gathered}
$$

Utilising Eq. (16), the general solution for the dust phase velocity is written as:

$$
\bar{V}(R, s)=\frac{\bar{U}(R, s)}{1+s \sigma}=\left[A_{1} I_{0}(R \delta)+A_{2} K_{0}(R \delta)+\frac{H a^{2} K_{v}}{s \delta^{2}}\right] \frac{1}{1+s \sigma} .
$$

The skin frictions on the outer surface of the inner cylinder and the inner surface of the outer cylinder, respectively, for the dust phase are given as:

$$
\begin{gathered}
\bar{\tau}_{1} *(1, s)=\left.\frac{d}{d R} \bar{V}(1, s)\right|_{R=1}=\frac{\delta}{1+s \sigma}\left[A_{1} I_{1}(\delta)-A_{2} K_{1}(\delta)\right], \\
\bar{\tau}_{\lambda} *(\lambda, s)=\left.\frac{d}{d R} \bar{V}(\lambda, s)\right|_{R=\lambda}=\frac{\delta}{1+s \sigma}\left[A_{1} I_{1}(\lambda \delta)-A_{2} K_{1}(\lambda \delta)\right] .
\end{gathered}
$$

\subsection{Case II: accelerated motion}

In order to achieve the uniformly accelerated movement of the outer cylinder for the fluid phase and dust phase, the value $n=1$ has been taken in Eqs. (9) and (11) to correspond to the case of the accelerated motion. Hence, the equation governing the binary mixture is written as:

$$
\begin{gathered}
\frac{\partial U}{\partial t}=\frac{\partial^{2} U}{\partial R^{2}}+\frac{1}{R} \frac{\partial U}{\partial R}-\mathrm{Ha}^{2}\left(U-K_{v} t\right)+\frac{\alpha}{\sigma}(V-U), \\
\sigma \frac{\partial V}{\partial t}=(U-V),
\end{gathered}
$$

with the concerned initial and boundary conditions

$$
\begin{aligned}
& t \leq 0 ; U=0 ; 1 \leq R \leq \lambda, \\
& t>0\left\{\begin{array}{l}
U=0 \text { at } R=1 \\
U=t \text { at } R=\lambda
\end{array}\right.
\end{aligned}
$$

Appling the Laplace transform technique, Eqs. (27)-(29) can be written as:

$$
\begin{gathered}
\frac{d^{2} \bar{U}}{d R^{2}}+\frac{1}{R} \frac{d \bar{U}}{d R}-\left(s+H a^{2}\right) \bar{U}+\frac{H a^{2} K_{v}}{s^{2}}+\frac{\alpha}{\sigma}(\bar{V}-\bar{U})=0, \\
s \sigma \bar{V}=\bar{U}-\bar{V},
\end{gathered}
$$


subject to the modified boundary conditions

$$
\left\{\begin{array}{c}
\bar{U}=0 \text { at } R=1 \\
\bar{U}=\frac{1}{s^{2}} \text { at } R=\lambda
\end{array}\right.
$$

Equation (31) can be otherwise written as:

$$
\bar{V}-\bar{U}=\frac{-s \sigma}{1+s \sigma} \bar{U}
$$

Putting (33) into (30), we get

$$
\frac{d^{2} \bar{U}}{d R^{2}}+\frac{1}{R} \frac{d \bar{U}}{d R}-\left(s+\mathrm{Ha}^{2}+\frac{\alpha s}{1+s \sigma}\right) \bar{U}=-\frac{\mathrm{Ha}^{2} K_{v}}{s^{2}} .
$$

The non-homogeneous linear differential equation in (34) is transformed following Jha and Apere [9], Jha and Gambo [37, 38] and Tsangaris et al. [42]:

$$
\bar{U}(R, s)=\bar{F}(R, s)+\frac{\mathrm{Ha}^{2} K_{v}}{s^{2} \delta^{2}},
$$

where $\overline{\mathrm{F}}(\mathrm{R}, \mathrm{s})=\mathrm{A}_{3} \mathrm{I}_{0}(\mathrm{R})+\mathrm{A}_{4} \mathrm{~K}_{0}(\mathrm{R})$.

Consequently, the solution of the fluid phase velocity for the accelerated motion under the associated boundary conditions in (32) is presented as:

$$
\bar{U}(R, s)=A_{3} I_{0}(R \delta)+A_{4} K_{0}(R \delta)+\frac{\mathrm{Ha}^{2} K_{v}}{s^{2} \delta^{2}},
$$

and the exact expression for $\mathrm{A}_{3}$ and $\mathrm{A}_{4}$ are given in the "Appendix" section.

The skin frictions for the fluid phase at $\mathrm{R}=1$ and $\mathrm{R}=\lambda$ are computed by differentiating Eq. (36) and are given below as:

$$
\begin{gathered}
\bar{\tau}_{1}(1, s)=\left.\frac{d}{d R} \bar{U}(1, s)\right|_{R=1}=\delta\left[A_{3} I_{1}(\delta)-A_{4} K_{1}(\delta)\right], \\
\bar{\tau}_{\lambda}(\lambda, s)=\left.\frac{d}{d R} \bar{U}(\lambda, s)\right|_{R=\lambda}=\delta\left[A_{3} I_{1}(\lambda \delta)-A_{4} K_{1}(\lambda \delta)\right] .
\end{gathered}
$$

Employing Eqs. (33) and (36), the solution of the dust phase velocity for the accelerated motion is given as:

$$
\bar{V}(R, s)=\frac{\bar{U}(R, s)}{1+s \sigma}=\frac{1}{1+s \sigma}\left[A_{3} I_{0}(R \delta)+A_{4} K_{0}(R \delta)+\frac{\mathrm{Ha}^{2} K_{v}}{s^{2} \delta^{2}}\right] .
$$

The drag on the outer surface of the inner cylinder and the inner surface of the outer cylinder, respectively, for the dust phase is given as:

$$
\begin{gathered}
\bar{\tau}_{1} *(1, s)=\left.\frac{d}{d R} \bar{V}(1, s)\right|_{R=1}=\frac{\delta}{1+s \sigma}\left[A_{3} I_{1}(\delta)-A_{4} K_{1}(\delta)\right] \\
\bar{\tau}_{\lambda} *(\lambda, s)=\left.\frac{d}{d R} \bar{V}(\lambda, s)\right|_{R=\lambda}=\frac{\delta}{1+s \sigma}\left[A_{3} I_{1}(\lambda \delta)-A_{4} K_{1}(\lambda \delta)\right] .
\end{gathered}
$$

\subsection{Riemann-sum approximation (RSA)}

It is principal to note that all the derived solutions in the previous sections are in Laplace domain and are to be inverted to time domain so as to determine the fluid phase velocity, dust phase velocity and skin frictions for both impulsive and accelerated motion. Due to the intricacy of the closed form solutions, the classical Laplace inversion appears inadequate. Hence, 
we adopted the use of a numerical inversion technique based on Riemann-Sum Approximation (RSA). In this method, a function of the Laplace domain can be transformed to a function of time domain as follows:

$$
\begin{gathered}
U(R, t)=\frac{\mathrm{e}^{\varepsilon t}}{t}\left[\frac{\bar{U}(R, s)}{2}+\operatorname{Re}\left(\sum_{n=1}^{W} \bar{U}\left(R, \varepsilon+\frac{i n \pi}{t}\right)\right)(-1)^{n}\right], \\
V(R, t)=\frac{\mathrm{e}^{\varepsilon t}}{t}\left[\frac{\bar{V}(R, s)}{2}+\operatorname{Re}\left(\sum_{n=1}^{W} \bar{V}\left(R, \varepsilon+\frac{i n \pi}{t}\right)\right)(-1)^{n}\right], \\
\tau(R, t)=\frac{\mathrm{e}^{\varepsilon t}}{t}\left[\frac{\bar{\tau}(R, s)}{2}+\operatorname{Re}\left(\sum_{n=1}^{W} \bar{\tau}\left(R, \varepsilon+\frac{i n \pi}{t}\right)\right)(-1)^{n}\right], \\
\tau *(R, t)=\frac{\mathrm{e}^{\varepsilon t}}{t}\left[\frac{\bar{\tau} *(R, s)}{2}+\operatorname{Re}\left(\sum_{n=1}^{W} \bar{\tau} *\left(R, \varepsilon+\frac{i n \pi}{t}\right)\right)(-1)^{n}\right],
\end{gathered}
$$

where Re represents the real part of the summation, $\mathrm{i}$ is the imaginary unit, $\mathrm{W}$ is the number of terms involved in the summation, and $\varepsilon$ is the real part of the Bromwich contour that is used in inverting Laplace transform. The Riemann-Sum Approximation (RSA) for the Laplace inversion involves a single summation for the numerical computation, of which its exactness is dependent on the value of $\varepsilon$ and the truncation error prescribed by W. Following Tzou [43], the stability of the solution is best achieved by taking $\varepsilon t=4.7$.

\subsection{Exact solution (ES)}

In an effort to illustrate how efficient the numerical inversion method adopted in transforming the Laplace domain solution to time domain is, the steady state solution is computed. This is accomplished by taking $\alpha=0$ or $\sigma \rightarrow \infty$ or $\frac{\partial()}{\partial t}=0$ in Eqs. (12) and (13) with the relevant boundary conditions. It is anticipated that steady state solution and transient solution will match at large time. In essence, at large time, the time-dependent solution coincides with the exact solution. Consequently, Eqs. $(12,13,14)$ reduce to:

$$
\begin{gathered}
\frac{d^{2} U_{s}}{d R^{2}}+\frac{1}{R} \frac{d U_{s}}{d R}-\mathrm{Ha}^{2}\left(U_{s}-K_{v}\right)=0, \\
\left\{\begin{array}{l}
U_{s}=0 \text { at } R=1 \\
U_{s}=1 \text { at } R=\lambda .
\end{array}\right.
\end{gathered}
$$

Following the approach of Jha and Apere [9], Jha and Gambo [37, 38] and Tsangaris et al. [42], the solution of Eq. (46) under boundary condition (47) is given as:

$$
U_{s}(R)=\left[A_{5} I_{0}(\mathrm{RHa})+A_{6} K_{0}(\mathrm{RHa})\right]+K_{v}
$$

where $\mathrm{A}_{5}$ and $\mathrm{A}_{6}$ are given in the "Appendix" section.

Differentiating Eq. (48) at $R=1$ and $\mathrm{R}=\lambda$, respectively, gives the steady state skin friction:

$$
\begin{gathered}
\tau_{s 1}=\left.\frac{d U_{s}}{d R}\right|_{R=1}=\mathrm{Ha}\left[A_{5} I_{1}(\mathrm{Ha})-A_{6} K_{1}(\mathrm{Ha})\right], \\
\tau_{s \lambda}=\left.\frac{d U_{s}}{d R}\right|_{R=\lambda}=\mathrm{Ha}\left[A_{5} I_{1}(\lambda \mathrm{Ha})-A_{6} K_{1}(\lambda \mathrm{Ha})\right] .
\end{gathered}
$$


Table 1 Numerical comparison for transient state impulsive fluid phase velocity obtained using Riemann-Sum Approximation (RSA) and exact solution (ES) $(\mathrm{Ha}=1.0, \alpha=0.3, \sigma=0.1)$

\begin{tabular}{|c|c|c|c|c|c|c|c|c|c|}
\hline \multirow[t]{2}{*}{$\bar{t}$} & \multirow[t]{2}{*}{$R$} & \multicolumn{2}{|c|}{$K_{v}=0.0$} & \multicolumn{2}{|c|}{$K_{v}=0.5$} & \multicolumn{2}{|c|}{$K_{v}=1.0$} & \multicolumn{2}{|c|}{$K_{v}=1.5$} \\
\hline & & RSA & ES & RSA & ES & RSA & ES & RSA & ES \\
\hline \multirow[t]{4}{*}{0.06} & 1.2 & 0.0223 & 0.2250 & 0.0405 & 0.2647 & 0.0588 & 0.3044 & 0.0770 & 0.3440 \\
\hline & 1.4 & 0.0859 & 0.4237 & 0.1099 & 0.4798 & 0.1340 & 0.5359 & 0.1580 & 0.5920 \\
\hline & 1.6 & 0.2474 & 0.6116 & 0.2710 & 0.6653 & 0.2945 & 0.7190 & 0.3181 & 0.7727 \\
\hline & 1.8 & 0.5554 & 0.8005 & 0.5724 & 0.8352 & 0.5893 & 0.8699 & 0.6063 & 0.9047 \\
\hline \multirow[t]{4}{*}{0.2} & 1.2 & 0.1472 & 0.2250 & 0.1795 & 0.2647 & 0.2119 & 0.3044 & 0.2442 & 0.3440 \\
\hline & 1.4 & 0.3030 & 0.4237 & 0.3482 & 0.4798 & 0.3934 & 0.5359 & 0.4385 & 0.5920 \\
\hline & 1.6 & 0.4923 & 0.6116 & 0.5358 & 0.6653 & 0.5793 & 0.7190 & 0.6227 & 0.7727 \\
\hline & 1.8 & 0.7257 & 0.8005 & 0.7544 & 0.8352 & 0.7831 & 0.8699 & 0.8118 & 0.9047 \\
\hline \multirow[t]{4}{*}{0.4} & 1.2 & 0.2026 & 0.2250 & 0.2403 & 0.2647 & 0.2779 & 0.3044 & 0.3155 & 0.3440 \\
\hline & 1.4 & 0.3895 & 0.4237 & 0.4425 & 0.4798 & 0.4956 & 0.5359 & 0.5486 & 0.5920 \\
\hline & 1.6 & 0.5786 & 0.6116 & 0.6295 & 0.6653 & 0.6803 & 0.7190 & 0.7312 & 0.7727 \\
\hline & 1.8 & 0.7805 & 0.8005 & 0.8136 & 0.8352 & 0.8466 & 0.8699 & 0.8796 & 0.9047 \\
\hline \multirow[t]{4}{*}{2.0} & 1.2 & 0.2251 & 0.2250 & 0.2647 & 0.2647 & 0.3044 & 0.3044 & 0.3441 & 0.3440 \\
\hline & 1.4 & 0.4237 & 0.4237 & 0.4798 & 0.4798 & 0.5359 & 0.5359 & 0.5921 & 0.5920 \\
\hline & 1.6 & 0.6117 & 0.6116 & 0.6654 & 0.6653 & 0.7191 & 0.7190 & 0.7728 & 0.7727 \\
\hline & 1.8 & 0.8006 & 0.8005 & 0.8353 & 0.8352 & 0.8700 & 0.8699 & 0.9047 & 0.9047 \\
\hline
\end{tabular}

In an attempt to authenticate the proficiency of the numerical inversing technique, numerical values obtained using Riemann-Sum Approximation (RSA) and exact solution (ES) have been tabulated. It is seen that at large time, Riemann-Sum Approximation coincides with the exact solution (ES). (See Tables 1, 2, 3, 4).

\section{Results and discussion}

In this section, we examine the effect of time $(t)$, Hartmann number (Ha), velocity of applied magnetic field $\left(K_{v}\right)$, varying mass parameter $(\alpha)$ and relaxation time $(\sigma)$ on the flow formation. In order to achieve this, a MATLAB program has been written to generate plots and numerical values for the velocities and skin frictions of the fluid phase and dust phase. In the course of our plots and computation, four values of applied magnetic field $\left(K_{v}\right)$ were selected. Here, we consider the case when the outer cylinder is subjected to impulsive movement and the case when the flow is due to the accelerated movement of the outer cylinder. All through the present analysis, figures labelled (a) showcase the component of fluid phase and figures labelled (b) depict the component of dust phase as seen in Figs. 2, 3, 4, 5, 6, 7, 8, 9, 10, 11 , $12,13$.

Figure 2 illustrates the action of time $(t)$ on local velocity for the fluid phase and dust phase of an impulsively moving wall. It can be seen that a growing time $(t)$ is accompanied by an increase in velocity for the fluid phase and dust phase, respectively, in all four cases of applied magnetic field $\left(K_{v}\right)$. We carefully observe that maximum velocity profiles are borne out when the velocity of applied magnetic field $\left(K_{v}=1.5\right)$ is greater than the velocity of the moving cylinder for both fluid phase and dust phase. However, a slightly different behaviour 
Table 2 Numerical comparison for transient state impulsive dust phase velocity obtained using Riemann-Sum Approximation (RSA) and exact solution $(\mathrm{ES})(\mathrm{Ha}=1.0, \alpha=0.3, \sigma=0.1)$

\begin{tabular}{|c|c|c|c|c|c|c|c|c|c|}
\hline \multirow[t]{2}{*}{$\mathrm{t}$} & \multirow[t]{2}{*}{$\mathrm{R}$} & \multicolumn{2}{|c|}{$K_{v}=0.0$} & \multicolumn{2}{|c|}{$K_{v}=0.5$} & \multicolumn{2}{|c|}{$K_{v}=1.0$} & \multicolumn{2}{|c|}{$K_{v}=1.5$} \\
\hline & & RSA & ES & RSA & ES & RSA & ES & RSA & ES \\
\hline \multirow[t]{4}{*}{0.06} & 1.2 & 0.0027 & 0.2250 & 0.0079 & 0.2647 & 0.0131 & 0.3044 & 0.0183 & 0.3440 \\
\hline & 1.4 & 0.0138 & 0.4237 & 0.0203 & 0.4798 & 0.0268 & 0.5359 & 0.0333 & 0.5920 \\
\hline & 1.6 & 0.0552 & 0.6116 & 0.0616 & 0.6653 & 0.0680 & 0.7190 & 0.0744 & 0.7727 \\
\hline & 1.8 & 0.1753 & 0.8005 & 0.1802 & 0.8352 & 0.1852 & 0.8699 & 0.1901 & 0.9047 \\
\hline \multirow[t]{4}{*}{0.2} & 1.2 & 0.0817 & 0.2250 & 0.1043 & 0.2647 & 0.1270 & 0.3044 & 0.1496 & 0.3440 \\
\hline & 1.4 & 0.1833 & 0.4237 & 0.2145 & 0.4798 & 0.2456 & 0.5359 & 0.2767 & 0.5920 \\
\hline & 1.6 & 0.3340 & 0.6116 & 0.3640 & 0.6653 & 0.3941 & 0.7190 & 0.4242 & 0.7727 \\
\hline & 1.8 & 0.5565 & 0.8005 & 0.5768 & 0.8352 & 0.5972 & 0.8699 & 0.6175 & 0.9047 \\
\hline \multirow[t]{4}{*}{0.4} & 1.2 & 0.1744 & 0.2250 & 0.2089 & 0.2647 & 0.2434 & 0.3044 & 0.2779 & 0.3440 \\
\hline & 1.4 & 0.3432 & 0.4237 & 0.3917 & 0.4798 & 0.4401 & 0.5359 & 0.4885 & 0.5920 \\
\hline & 1.6 & 0.5274 & 0.6116 & 0.5738 & 0.6653 & 0.6203 & 0.7190 & 0.6668 & 0.7727 \\
\hline & 1.8 & 0.7388 & 0.8005 & 0.7692 & 0.8352 & 0.7996 & 0.8699 & 0.8300 & 0.9047 \\
\hline \multirow[t]{4}{*}{2.0} & 1.2 & 0.2251 & 0.2250 & 0.2647 & 0.2647 & 0.3044 & 0.3044 & 0.3441 & 0.3440 \\
\hline & 1.4 & 0.4237 & 0.4237 & 0.4798 & 0.4798 & 0.5359 & 0.5359 & 0.5920 & 0.5920 \\
\hline & 1.6 & 0.6117 & 0.6116 & 0.6654 & 0.6653 & 0.7191 & 0.7190 & 0.7728 & 0.7727 \\
\hline & 1.8 & 0.8006 & 0.8005 & 0.8353 & 0.8352 & 0.8700 & 0.8699 & 0.9047 & 0.9047 \\
\hline
\end{tabular}

(a)

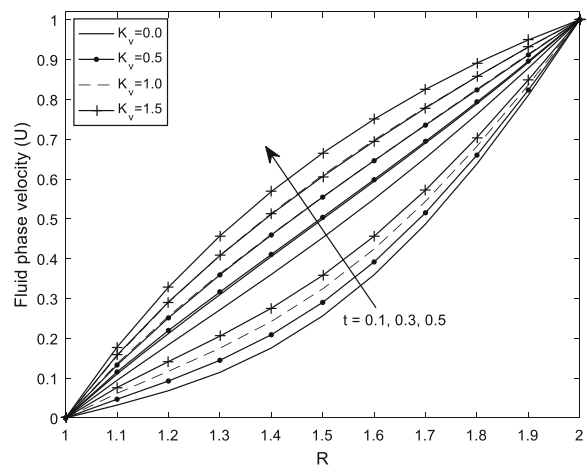

(b)

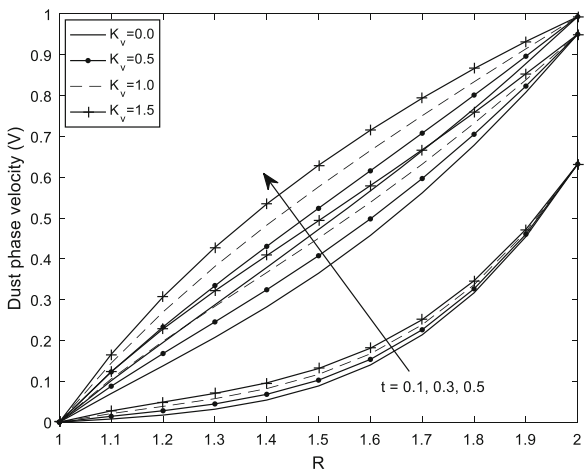

Fig. 2 Impulsive velocity profile for variations of time $(t)$ for fluid phase $(\mathbf{a})$ and dust phase $(\mathbf{b})(\mathrm{Ha}=1.0, \alpha=$ $0.3, \sigma=0.1)$

is perceived as time $(t)$ is increased for the dust phase velocity. It is seen that the increase is not significant towards the outer wall in comparison with the fluid phase velocity when $t=0.1$. This is due to lagging caused by the dust particle in the binary mixture when the motion sets in.

The impact of time $(t)$ on velocity profiles for fluid phase and dust phase when the movement of the outer cylinder is accelerated is presented in Fig. 3. Here one finds that as time $(t)$ is increased, both components of the velocities increase. However, the relaxation time parameter $(\sigma)$ plays an important role in reducing the magnitude of the dust phase velocity. 
Table 3 Numerical comparison for transient state impulsive fluid phase skin friction at $\mathrm{R}=1$ obtained using Riemann-Sum Approximation (RSA) and exact solution (ES) $(\lambda=1.8, \alpha=0.3, \sigma=0.1)$.

\begin{tabular}{|c|c|c|c|c|c|c|c|c|c|}
\hline \multirow[t]{2}{*}{$\mathrm{t}$} & \multirow[t]{2}{*}{$\mathrm{Ha}$} & \multicolumn{2}{|c|}{$K_{v}=0.0$} & \multicolumn{2}{|c|}{$K_{v}=0.5$} & \multicolumn{2}{|c|}{$K_{v}=1.0$} & \multicolumn{2}{|c|}{$K_{v}=1.5$} \\
\hline & & RSA & $\mathrm{ES}$ & RSA & ES & RSA & ES & RSA & ES \\
\hline \multirow[t]{5}{*}{0.06} & 1.0 & 0.3678 & 1.5316 & 0.5075 & 1.7461 & 0.6472 & 1.9605 & 0.7869 & 2.1749 \\
\hline & 1.5 & 0.3480 & 1.3509 & 0.6550 & 1.8041 & 0.9620 & 2.2573 & 1.2690 & 2.7105 \\
\hline & 2.0 & 0.3223 & 1.1436 & 0.8506 & 1.8877 & 1.3790 & 2.6318 & 1.9073 & 3.3759 \\
\hline & 2.5 & 0.2921 & 0.9356 & 1.0850 & 1.9972 & 1.8778 & 3.0589 & 2.6707 & 4.1206 \\
\hline & 3.0 & 0.2592 & 0.7443 & 1.3480 & 2.1316 & 2.4368 & 3.5189 & 3.5256 & 4.9062 \\
\hline \multirow[t]{5}{*}{0.2} & 1.0 & 1.2552 & 1.5316 & 1.4525 & 1.7461 & 1.6499 & 1.9605 & 1.8472 & 2.1749 \\
\hline & 1.5 & 1.1303 & 1.3509 & 1.5524 & 1.8041 & 1.9744 & 2.2573 & 2.3965 & 2.7105 \\
\hline & 2.0 & 0.9799 & 1.1436 & 1.6820 & 1.8877 & 2.3841 & 2.6318 & 3.0863 & 3.3759 \\
\hline & 2.5 & 0.8209 & 0.9356 & 1.8351 & 1.9972 & 2.8494 & 3.0589 & 3.8636 & 4.1206 \\
\hline & 3.0 & 0.6672 & 0.7443 & 2.0066 & 2.1316 & 3.3459 & 3.5189 & 4.6852 & 4.9062 \\
\hline \multirow[t]{5}{*}{0.4} & 1.0 & 1.4732 & 1.5316 & 1.6841 & 1.7461 & 1.8951 & 1.9605 & 2.1061 & 2.1749 \\
\hline & 1.5 & 1.3060 & 1.3509 & 1.7532 & 1.8041 & 2.2004 & 2.2573 & 2.6476 & 2.7105 \\
\hline & 2.0 & 1.1118 & 1.1436 & 1.8482 & 1.8877 & 2.5846 & 2.6318 & 3.3210 & 3.3759 \\
\hline & 2.5 & 0.9142 & 0.9356 & 1.9676 & 1.9972 & 3.0211 & 3.0589 & 4.0746 & 4.1206 \\
\hline & 3.0 & 0.7304 & 0.7443 & 2.1099 & 2.1316 & 3.4894 & 3.5189 & 4.8689 & 4.9062 \\
\hline \multirow[t]{5}{*}{3.0} & 1.0 & 1.5318 & 1.5316 & 1.7464 & 1.7461 & 1.960 & 1.9605 & 2.1749 & 2.1749 \\
\hline & 1.5 & 1.3510 & 1.3509 & 1.8042 & 1.8041 & 2.2573 & 2.2573 & 2.7104 & 2.7105 \\
\hline & 2.0 & 1.1437 & 1.1436 & 1.8876 & 1.8877 & 2.6316 & 2.6318 & 3.3758 & 3.3759 \\
\hline & 2.5 & 0.9357 & 0.9356 & 1.9972 & 1.9972 & 3.0588 & 3.0589 & 4.1205 & 4.1206 \\
\hline & 3.0 & 0.7444 & 0.7443 & 2.1315 & 2.1316 & 3.5189 & 3.5189 & 4.9063 & 4.9062 \\
\hline
\end{tabular}

(a)

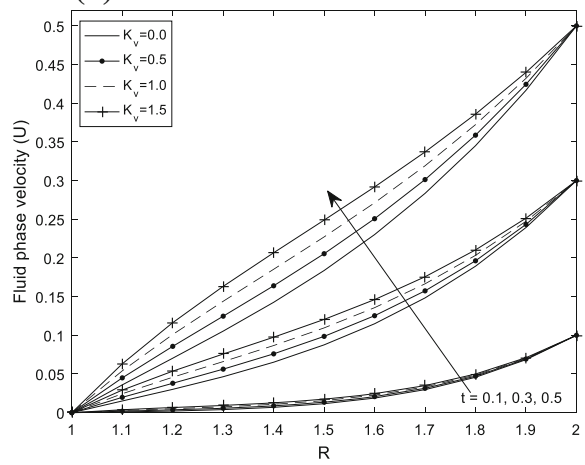

(b)

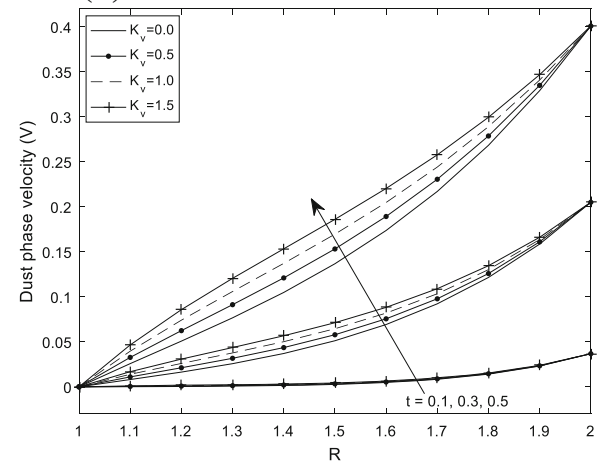

Fig. 3 Accelerated velocity profile for variations of time $(t)$ for fluid phase $(\mathbf{a})$ and dustphase $(b)(\mathrm{Ha}=$ $1.0, \alpha=0.3, \sigma=0.1)$

The influence of Hartmann number (Ha) on the fluid phase velocity and dust phase velocity is demonstrated in Fig. 4a and b for an impulsively moving wall. As expected, the classical effect of Hartmann number (Ha) is to retard local velocity in the absence of applied magnetic field $\left(K_{v}=0.0\right)$. Nevertheless, with the amplification of the strength of applied magnetic 
Table 4 Numerical comparison for transient state impulsive dust phase skin friction at $R=1$ obtained using Riemann-Sum Approximation (RSA) and exact solution (ES) $(\lambda=1.8, \alpha=0.3, \sigma=0.1)$.

\begin{tabular}{|c|c|c|c|c|c|c|c|c|c|}
\hline \multirow[t]{2}{*}{$\mathrm{t}$} & \multirow[t]{2}{*}{$\mathrm{Ha}$} & \multicolumn{2}{|c|}{$K_{v}=0.0$} & \multicolumn{2}{|c|}{$K_{v}=0.5$} & \multicolumn{2}{|c|}{$K_{v}=1.0$} & \multicolumn{2}{|c|}{$K_{v}=1.5$} \\
\hline & & RSA & ES & RSA & ES & RSA & ES & RSA & ES \\
\hline \multirow[t]{5}{*}{0.06} & 1.0 & 0.0520 & 1.5316 & 0.0971 & 1.7461 & 0.1423 & 1.9605 & 0.1875 & 2.1749 \\
\hline & 1.5 & 0.0495 & 1.3509 & 0.1496 & 1.8041 & 0.2497 & 2.2573 & 0.3498 & 2.7105 \\
\hline & 2.0 & 0.0464 & 1.1436 & 0.2206 & 1.8877 & 0.3948 & 2.6318 & 0.5690 & 3.3759 \\
\hline & 2.5 & 0.0426 & 0.9356 & 0.3076 & 1.9972 & 0.5726 & 3.0589 & 0.8376 & 4.1206 \\
\hline & 3.0 & 0.0384 & 0.7443 & 0.4082 & 2.1316 & 0.7779 & 3.5189 & 1.1476 & 4.9062 \\
\hline \multirow[t]{5}{*}{0.2} & 1.0 & 0.7877 & 1.5316 & 0.9368 & 1.7461 & 1.0858 & 1.9605 & 1.2349 & 2.1749 \\
\hline & 1.5 & 0.7179 & 1.3509 & 1.0397 & 1.8041 & 1.3616 & 2.2573 & 1.6834 & 2.7105 \\
\hline & 2.0 & 0.6322 & 1.1436 & 1.1739 & 1.8877 & 1.7156 & 2.6318 & 2.2573 & 3.3759 \\
\hline & 2.5 & 0.5394 & 0.9356 & 1.3321 & 1.9972 & 2.1248 & 3.0589 & 2.9174 & 4.1206 \\
\hline & 3.0 & 0.4473 & 0.7443 & 1.5079 & 2.1316 & 2.5685 & 3.5189 & 3.6291 & 4.9062 \\
\hline \multirow[t]{5}{*}{0.4} & 1.0 & 1.3382 & 1.5316 & 1.5381 & 1.7461 & 1.7380 & 1.9605 & 1.9379 & 2.1749 \\
\hline & 1.5 & 1.1928 & 1.3509 & 1.6181 & 1.8041 & 2.0435 & 2.2573 & 2.4688 & 2.7105 \\
\hline & 2.0 & 1.0220 & 1.1436 & 1.7253 & 1.8877 & 2.4287 & 2.6318 & 3.1321 & 3.3759 \\
\hline & 2.5 & 0.8460 & 0.9356 & 1.8565 & 1.9972 & 2.8670 & 3.0589 & 3.8775 & 4.1206 \\
\hline & 3.0 & 0.6803 & 0.7443 & 2.0087 & 2.1316 & 3.3371 & 3.5189 & 4.6655 & 4.9062 \\
\hline \multirow[t]{5}{*}{3.0} & 1.0 & 1.5318 & 1.5316 & 1.7462 & 1.7461 & 1.9607 & 1.9605 & 2.1751 & 2.1749 \\
\hline & 1.5 & 1.3510 & 1.3509 & 1.8042 & 1.8041 & 2.2575 & 2.2573 & 2.7107 & 2.7105 \\
\hline & 2.0 & 1.1437 & 1.1436 & 1.8879 & 1.8877 & 2.6320 & 2.6318 & 3.3762 & 3.3759 \\
\hline & 2.5 & 0.9357 & 0.9356 & 1.9974 & 1.9972 & 3.0592 & 3.0589 & 4.1209 & 4.1206 \\
\hline & 3.0 & 0.7444 & 0.7443 & 2.1318 & 2.1316 & 3.5192 & 3.5189 & 4.9066 & 4.9062 \\
\hline
\end{tabular}

(a)

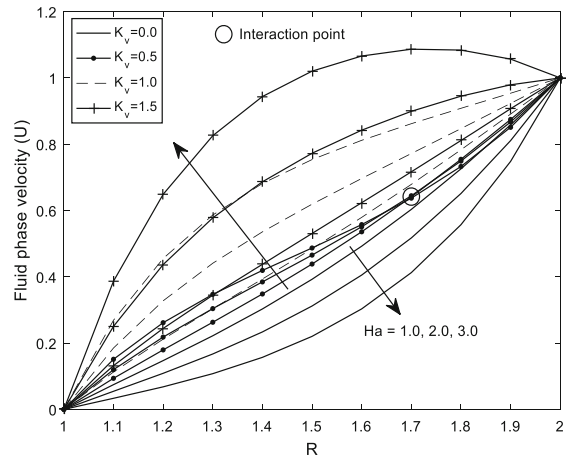

(b)

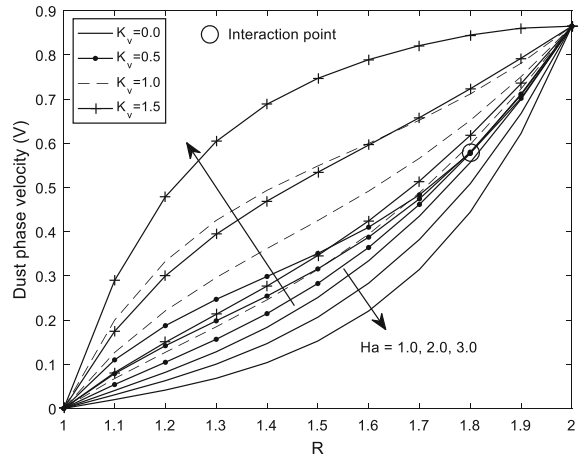

Fig. 4 Impulsive velocity profile for variations of Hartmann number (Ha) for fluid phase (a) and dust phase (b) $(\mathrm{t}=0.2, \alpha=0.3, \sigma=0.1)$

field $\left(K_{v}\right)$, the Lorentz force is rendered less effective, and thus the effect of velocity of applied magnetic field $\left(K_{v}\right)$ becomes obvious even as Hartmann number (Ha) is enhanced, thereby accelerating the velocity for both fluid and dust phase. This can only be said with the application of velocity of magnetic field $\left(K_{v}>0.0\right)$. 
(a)

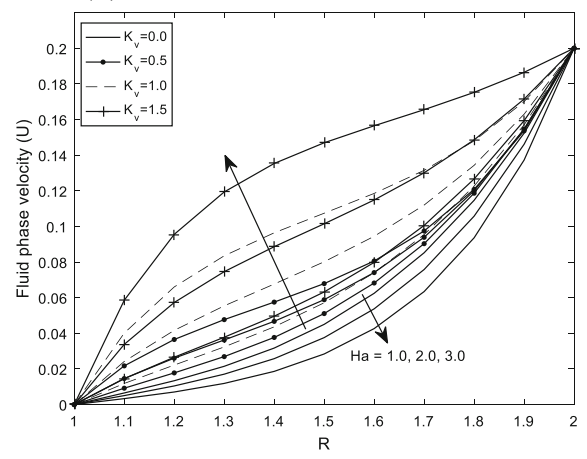

(b)

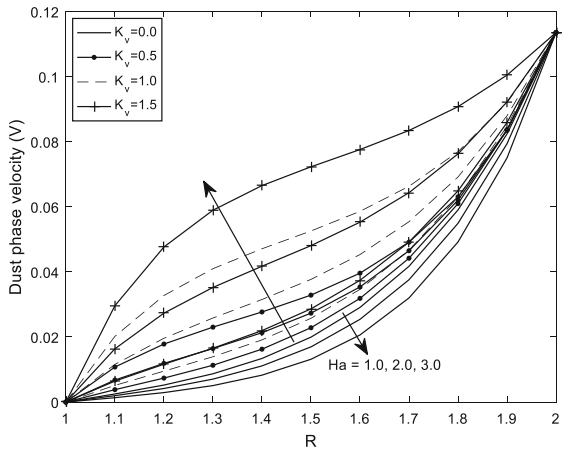

Fig. 5 Accelerated velocity profile for variations of Hartmann number (Ha) for fluid phase (a) and dust phase (b) $(\mathrm{t}=0.2, \alpha=0.3, \sigma=0.1)$

(a)

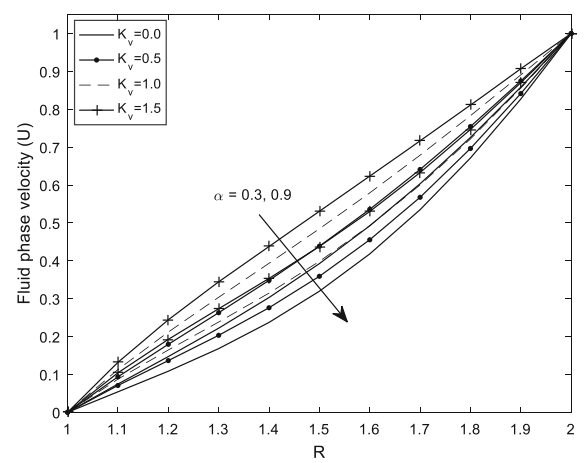

(b)

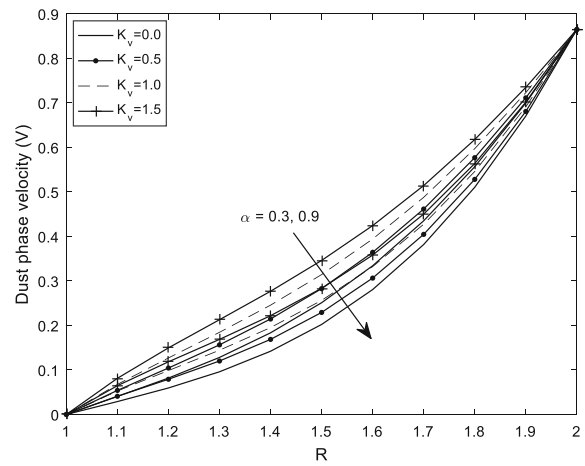

Fig. 6 Impulsive velocity profile for variations of varying mass parameter of dust particle $(\alpha)$ for fluid phase (a) and dust phase (b) $(t=0.2, \mathrm{Ha}=1.0, \sigma=0.1)$

Figure 5 shows the variation of velocity profiles for both fluid phase and dust phase for different values of Hartmann number (Ha) when the accelerated motion of the outer wall is considered. It is interesting to note that the retarding effect of Hartmann number (Ha) on fluid flow is noticed in the absence of applied magnetic field is $\left(K_{v}=0.0\right)$ for both components of velocity. A counter trend is observed when magnetic field $\left(K_{v}>0\right)$ is applied on the fluid. We note that the fluid velocity profiles increase as Hartmann number $(\mathrm{Ha})$ is increased. This can be ascribed to the increasing effect of the applied magnetic field $\left(K_{v}\right)$ overwhelming the Lorentz force. In addition, the increase is more pronounced for the fluid phase and higher magnetic field $\left(K_{v}\right)$.

Figures 6 and 7 exhibit the action of varying mass parameter $(\alpha)$ on the components of the velocity for an impulsively and accelerated moving wall respectively. It is seen that the increasing effect of the varying mass parameter $(\alpha)$ is to lower velocity.

The consequences of enhancing the strength of relaxation time $(\sigma)$ on the fluid and dust phases of an impulsively moving cylinder and accelerating moving cylinder are demonstrated in Figs. 8 and 9, respectively. A clear indication shows that the influence of the relaxation time $(\sigma)$ is to lessen the component of the dust velocity. This is ascribed to the fact that a longer time is taken to perturb the dust particles within the system thus retarding flow. 
(a)

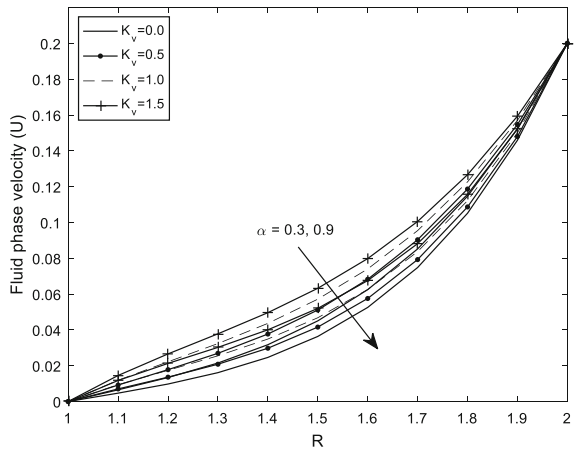

(b)

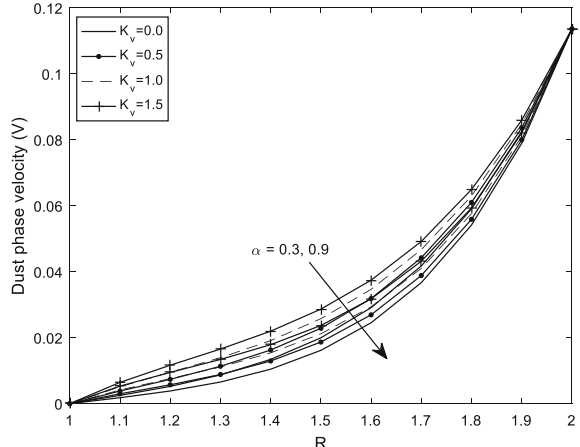

Fig. 7 Accelerated velocity profile for variations of varying mass parameter of dust particle $(\alpha)$ for fluid phase (a) and dust phase (b) $(t=0.2, \mathrm{Ha}=1.0, \sigma=0.1)$

(a)

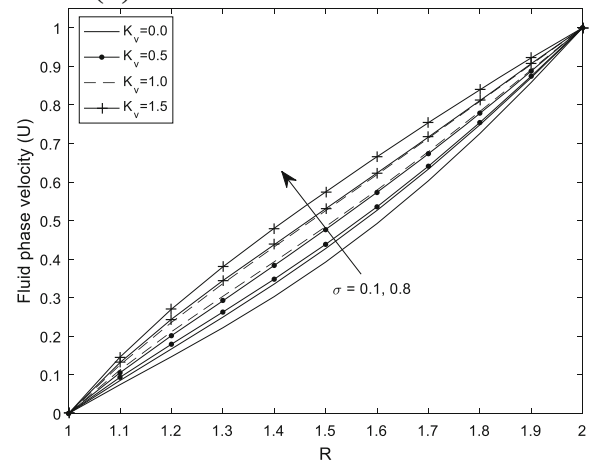

(b)

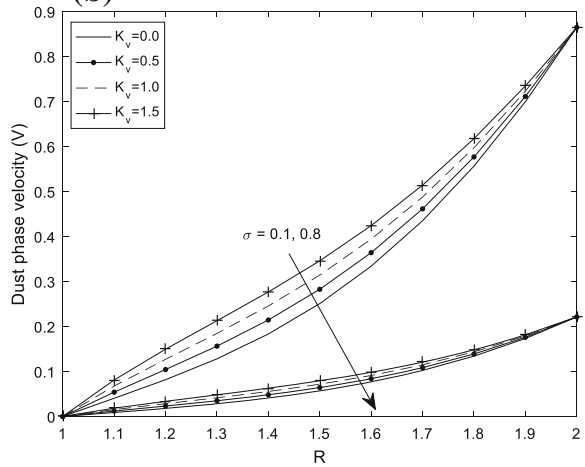

Fig. 8 Impulsive velocity profile for variations of relaxation time $(\sigma)$ for fluid phase (a) and dust phase (b) $(t=0.2, \alpha=0.3, \mathrm{Ha}=1.0)$

(a)

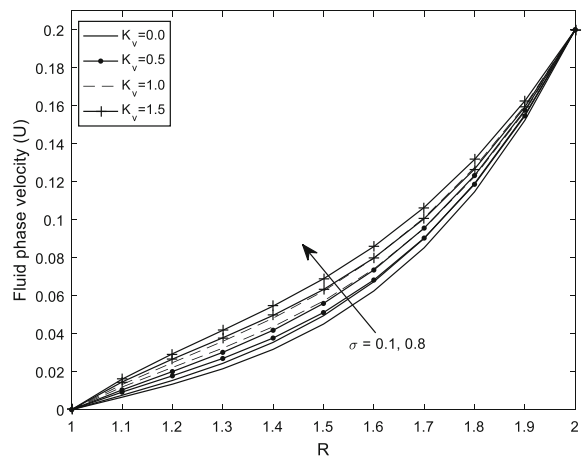

(b)

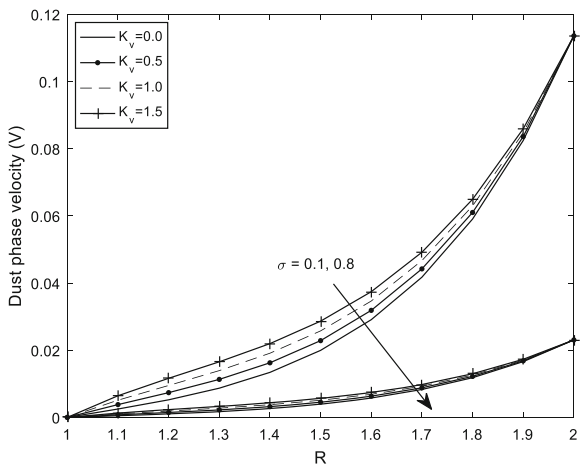

Fig. 9 Accelerated velocity profile for variations of relaxation time $(\sigma)$ for fluid phase (a) and dust phase (b) $(\mathrm{t}=0.2, \alpha=0.3, \mathrm{Ha}=1.0)$ 
(a)

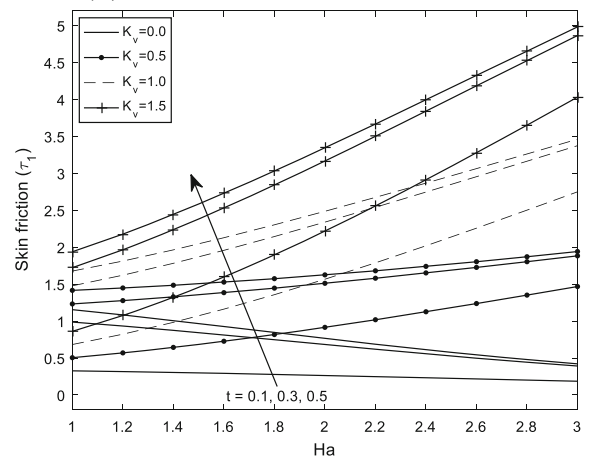

(b)

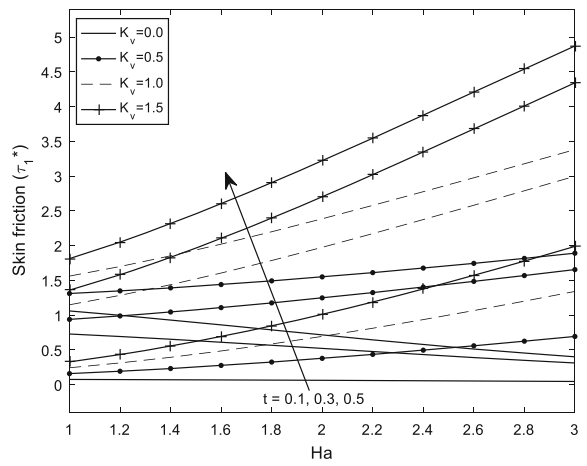

Fig. 10 Skin friction profile for variations of time $(t)$ of an impulsively moving wall for fluid phase (a) and dust $(\alpha=0.3, \sigma=0.1, R=1)$

(a)

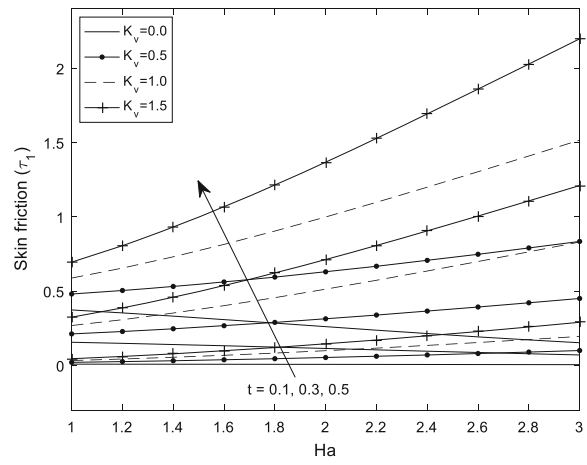

(b)

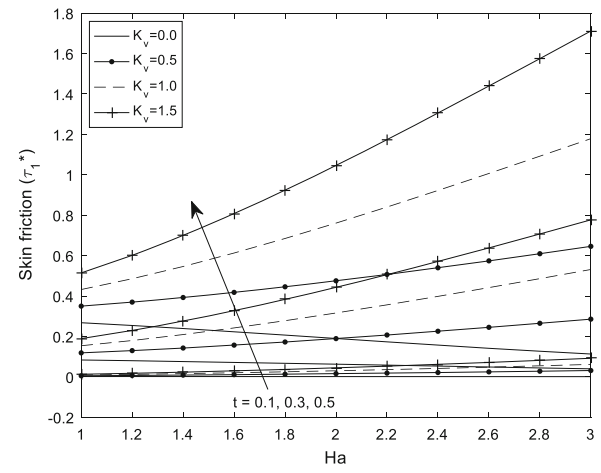

Fig. 11 Skin friction profile for variations of time $(t)$ of an accelerating moving wall for fluid phase (a) and dust $(\alpha=0.3, \sigma=0.1, R=1)$

Figures 10 and 11 describe the role of time $(t)$ and Hartmann number (Ha) on local skin friction at the surface of the outer cylinder for an impulsively and accelerating moving wall, respectively. It is clear from Fig. 10 that as time $(t)$ and Hartmann number (Ha) are amplified, there is a general increase in skin friction for both fluid phase and dust phase. A similar behaviour is observed for an accelerating moving cylinder as illustrated in Fig. 11. It is important to note that the increase is least in the absence of velocity of applied magnetic field $\left(K_{v}=0\right)$.

The impact of Hartmann number (Ha) on skin friction distribution at the inner surface of the outer cylinder for both fluid phase and dust phase as time $(t)$ is increasing for an impulsive and accelerated motion, respectively, is displayed in Figs. 12 and 13. We observed that as Hartmann number (Ha) is increased, the trend is seen to grow for all cases of velocity of applied magnetic field $\left(K_{v}\right)$. This is true for both cases of boundary movement expect for an impulsively moving dust particle. In addition, a higher profile for skin friction is seen for dust phase of an impulsively moving outer cylinder. 
(a)

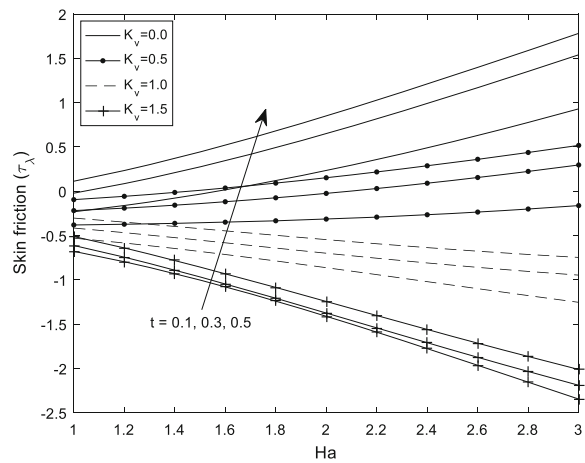

(b)

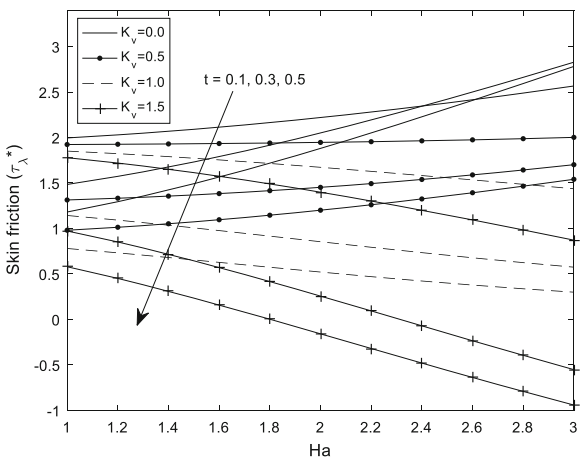

Fig. 12 Skin friction profile for variations of time $(t)$ of an impulsively moving wall for fluid phase (a) and dust $(\alpha=0.3, \sigma=0.1, R=\lambda)$

(a)

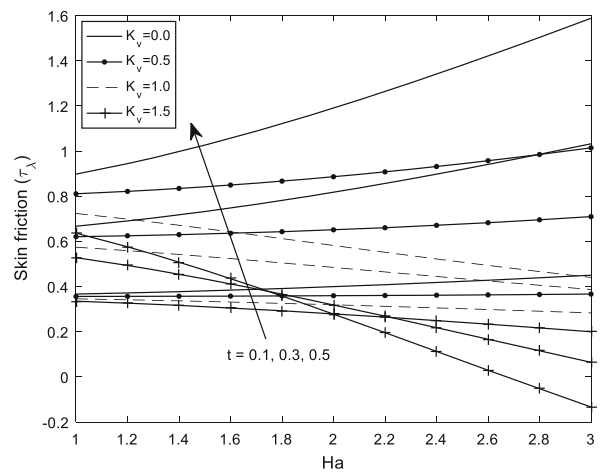

(b)

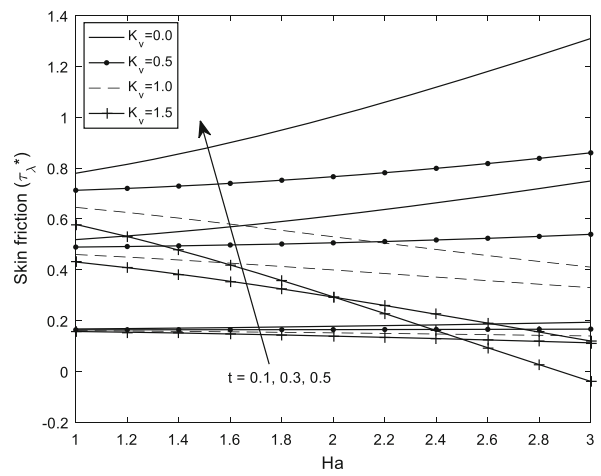

Fig. 13 Skin friction profile for variations of time $(t)$ of an accelerating moving wall for fluid phase (a) and dust $(\alpha=0.3, \sigma=0.1, R=\lambda)$

\section{Conclusions}

The MHD flow of a fluid saturated with particulate suspension under the influence of velocity of applied magnetic field based on Saffman's dusty fluid model has been discussed. The setup of this flow was done in such a way that the fluid flow in the annular gap was triggered by the impulsive movement or accelerated movement of the bounding wall in addition to the applied velocity of magnetic field $\left(K_{v}\right)$. The equations describing the flow have been solved with minimum error in the time domain using Laplace transformation and a numerical inversion method based on Riemann-Sum Approximation (RSA). The result was vetted by presenting a comparative exact solution. Notable outcomes of the study are given as follows:

i. Fluid phase velocity and dust phase velocity can be intensified by increasing time $(\mathrm{t})$ and strengthening the effect of applied magnetic field $\left(K_{v}\right)$.

ii. The components of velocity are improved by increasing Hartmann number (Ha) for both an impulsively moving wall and accelerated wall. Although this attribute is unnoticed in the absence of velocity of applied magnetic field $\left(K_{v}\right)$. This behaviour has captivating applications in hemodynamics and biofluid engineering. 
iii. Skin frictions on the surfaces of the inner and outer cylinders can be increased by increasing time $(t)$, respectively.

iv. Higher variable mass parameter $(\alpha)$ and suppression of velocity of applied magnetic field reduce the velocity profiles for dust phase and fluid phase.

v. Relaxation time parameter increases the fluid velocity distribution, while a contrary conduct is recorded for the dust phase velocity profile.

Acknowledgements The authors will like to thank the reviewers and editorial team for their immense contribution and will also like to dedicate the work to the memory of Late Chief Gambo B. Ahmed who passed away in the course of this research work.

Open Access This article is licensed under a Creative Commons Attribution 4.0 International License, which permits use, sharing, adaptation, distribution and reproduction in any medium or format, as long as you give appropriate credit to the original author(s) and the source, provide a link to the Creative Commons licence, and indicate if changes were made. The images or other third party material in this article are included in the article's Creative Commons licence, unless indicated otherwise in a credit line to the material. If material is not included in the article's Creative Commons licence and your intended use is not permitted by statutory regulation or exceeds the permitted use, you will need to obtain permission directly from the copyright holder. To view a copy of this licence, visit http://creativecommons.org/licenses/by/4.0/.

\section{Appendix}

$$
\begin{gathered}
A_{1}=\frac{\left(-\frac{\mathrm{Ha}^{2} K_{v}}{s \delta^{2}}\right) K_{1}(\lambda \delta)-\left(\frac{1}{s}-\frac{\mathrm{Ha}^{2} K_{v}}{s \delta^{2}}\right) K_{1}(\delta)}{I_{1}(\delta) K_{1}(\lambda \delta)-I_{1}(\lambda \delta) K_{1}(\delta)} ; A_{2}=\frac{\left(\frac{1}{s}-\frac{\mathrm{Ha}^{2} K_{v}}{s \delta^{2}}\right) I_{1}(\delta)-\left(-\frac{\mathrm{Ha}^{2} K_{v}}{s \delta^{2}}\right) I_{1}(\lambda \delta)}{I_{1}(\delta) K_{1}(\lambda \delta)-I_{1}(\lambda \delta) K_{1}(\delta)} ; \\
A_{3}=\frac{\left(-\frac{\mathrm{Ha}^{2} K_{v}}{s^{2} \delta^{2}}\right) K_{1}(\lambda \delta)-\left(\frac{1}{s^{2}}-\frac{\mathrm{Ha}^{2} K_{v}}{s^{2} \delta^{2}}\right) K_{1}(\delta)}{I_{1}(\delta) K_{1}(\lambda \delta)-I_{1}(\lambda \delta) K_{1}(\delta)} ; A_{4}=\frac{\left(\frac{1}{s^{2}}-\frac{\mathrm{Ha}^{2} K_{v}}{s^{2} \delta^{2}}\right) I_{1}(\delta)-\left(-\frac{\mathrm{Ha}^{2} K_{v}}{s^{2} \delta^{2}}\right) I_{1}(\lambda \delta)}{I_{1}(\delta) K_{1}(\lambda \delta)-I_{1}(\lambda \delta) K_{1}(\delta)} ; \\
A_{5}=\frac{-K_{v}\left\{K_{1}(\mathrm{Ha})+K_{1}(\lambda \mathrm{Ha})\right\}+K_{1}(\mathrm{Ha})}{I_{1}(\lambda \mathrm{Ha}) K_{1}(\mathrm{Ha})-K_{1}(\lambda \mathrm{Ha}) I_{1}(\mathrm{Ha})} ; A_{6}=\frac{K_{v}\left\{I_{1}(\mathrm{Ha})-I_{1}(\lambda \mathrm{Ha})\right\}-I_{1}(\mathrm{Ha})}{I_{1}(\lambda \mathrm{Ha}) K_{1}(\mathrm{Ha})-K_{1}(\lambda \mathrm{Ha}) I_{1}(\mathrm{Ha})} ;
\end{gathered}
$$

\section{References}

1. P.G. Saffman, On the stability of laminar flow of a dusty gas. J. Fluid Mech. 13, 120-128 (1962)

2. J.T.C. Liu, Flow induced by an oscillating infinite plat plate in a dusty gas. Phys. Fluids 9, 1716-1720 (1966)

3. S.K. Nag, R.N. Jana, N. Datta, Couettte flow of a dusty gas. Acta Mech. 33, 179-187 (1979)

4. A.S. Gupta, On the flow of an electrically conducting fluid near an accelerated plate in presence of a magnetic field. J. Phys. Soc. Jpn. 15, 1894-1897 (1960)

5. V.J. Rossow, On the flow of electrically conducting fluids over a flat plate in presence of a transverse magnetic field, NACA TN, 3971 (1957)

6. P. Mitra, P. Bhattacharyya, Unsteady hydromagnetic laminar flow of a conducting dusty fluid between two parallel plates started impulsively from rest. Acta Mech. 39, 171-182 (1981)

7. A.K. Vanita, Effect of velocity of applied magnetic field on natural convection over ramped type moving inner cylinder with ramped type temperature, International Journal of Mechanical Sciences, pp. 1-15 (2017)

8. B.K. Jha, C.A. Apere, Unsteady MHD Couette flows in an annuli: the riemann-sum approximation approach. J. Phys. Soc. Jpn. 79(12), 1-5 (2010)

9. B.K. Jha, C.A. Apere, Time-dependent MHD Couette flow in a porous annulus. Commun. Nonlinear Sci. Numer. Simulation 18, 1959-1969 (2013)

10. B.K. Jha, L.A. Azeez, M.O. Oni, Unsteady hydromagnetic-free convection flow with suction/injection. J. Taibah Univ. Sci. 13(1), 136-145 (2018)

11. N. Datta, S.K. Mishra, Boundary layer flow of a dusty fluid over a semi-infinite flat plate. Acta Mech. 42, 71-83 (1982)

12. H.A. Attia, Unsteady MHD flow and heat transfer of dusty fluid between parallel plates with variable physical properties. Appl. Math. Model. 26, 863-875 (2002) 
13. A. Kumar, A.K. Singh, Transient Magnetohydrodynamic Couette flow with ramped velocity. Int. J. Fluid Mech. Res. 37, 435-446 (2010)

14. B.J. Gireesha, B. Mahanthesh, R.S.R. Gorla, P.T. Manjunatha, Thermal radiation and Hall effects on boundary layer flow past a non-isothermal stretching surface embedded in porous medium with nonuniform heat source/sink and fluid-particle suspension. Heat Mass Transf. 52, 897-911 (2016)

15. B.J. Gireesha, G.S. Roopa, C.S. Bagewadi, Effect of viscous dissipation and heat source on flow and heat transfer of dusty fluid over unsteady stretching sheet. Appl. Math. Mech. (English Edition) 33(8), 1001-1014 (2012)

16. B.J. Gireesha, G.K. Ramesh, M.S. Abel, C.S. Bagewadi, Boundary layer flow and heat transfer of a dusty fluid flow over a stretching sheet with non-uniform heat source/sink. Int. J. Multiph. Flow 37, 977-982 (2011)

17. B.J. Gireesha, B. Mahanthesh, P.T. Manjunatha and R.S.R. Gorla, Numerical solution for hydromagnetic boundary layer flow and heat transfer past a stretching surface embedded in non-Darcy porous medium with fluid-particle suspension, J. Nigerian Math. Soc., pp. 1-19 (2015)

18. G.K. Ramesh, B.J. Gireesha, C.S. Bagewadi, MHD flow of a dusty fluid near the stagnation point over a permeable stretching sheet with non-uniform source/sink. Int. J. Heat Mass Transf. 55, 4900-4907 (2012)

19. G.K. Ramesh, B.J. Gireesha, Flow over a stretching sheet in a dusty fluid with radiation effect. J. Heat Tranf. 135, 1-6 (2013)

20. O.M. Prakash, O.D. Makinde, D. Kumar, Y.K. Dwivedi, Heat transfer to MHD oscillatory dusty fluid flow in a channel filled with a porous medium. Sadhana 40(4), 1273-1282 (2015)

21. Z. Abbas, J. Hasnain, M. Sajid, Effects of slip on MHD Flow of a dusty fluid over a stretching sheet through porous space. J. Eng. Thermophys. 28(1), 84-102 (2019)

22. H.A. Attia, K.M. Ewis, Magnetohydrodynamic flow of continuous dusty particles and non-Newtonian Darcy fluids between parallel plates. Adv. Mech. Eng. 11(6), 1-11 (2019)

23. B. Mahanthesh, N.S. Shashikumar, B.J. Gireesha, I.L. Animasaun, Effectiveness of Hall current and exponential heat source on unsteady heat transport of dusty TiO2-EO nanoliquid with nonlinear radiative heat. J. Comput. Design Eng. 6, 551-561 (2019)

24. M. Jalil, S. Asghar, S. Yasmeen, An exact solution of MHD boundary layer flow of dusty fluid over a stretching surface, Math. Problems Eng., pp. 1-5 (2017)

25. P.T. Manjunatha, B.J. Gireesha, B.C. Prasannakumara, Thermal analysis of conducting dusty fluid flow in a porous medium over a stretching cylinder in the presence of non-uniform source/sink. Int. J. Mech. Mater. Eng. 1(13), 1-10 (2014)

26. S. Manjunatha, B.J. Gireesha, Effects of variable viscosity and thermal conductivity on MHD flow and heat transfer of a dusty fluid, Ain Shams Eng. J., pp. 1-11 (2015)

27. B.J. Gireesha, K.R. Madhura, C.S. Bagewadi, Flow of an unsteady dusty fluid through porous media in a uniform pipe with sector of a circle as cross-section. Int. J. Pure Appl. Math. 76(1), 29-47 (2012)

28. S.M. Isa, N.F. Mohammad, Boundary layer flow of dusty fluid on a stretching sheet of another Quiescent Fluid. J. Phys. Conf. Ser. 819, 1-9 (2017)

29. O.D. Makinde, T. Chinyoka, MHD transient flows and heat transfer of dusty fluid in a channel with variable physical properties and Navier slip condition. Comput. Math. Appl. 60, 660-669 (2010)

30. T.S. Yusuf, D. Gambo, Impact of heat generation/absorption on transient natural convective flow in an annulus filled with porous material subject to isothermal and adiabatic boundaries. GEM Int. J. Geomath. 10(20), 1-16 (2019)

31. T.S. Yusuf, D. Gambo, Role of heat source/sink on time dependent free convective flow in a coaxial cylinder filled with porous material: a semi analytical approach. Int. J. Appl. Power Eng. (IJAPE) 8(1), $67-77(2020)$

32. J.J. Gambo, D. Gambo, On the effect of heat generation/absorption on magnetohydrodynamic free convective flow in a vertical annulus: an Adomian decomposition method. Heat Transf. 50(3), 2288-2302 (2021)

33. D. Gambo, J.J. Gambo, Role of suction/injection and slip flow on hydromagnetic free convective flow in a vertical coaxial cylinder under the influence of radial magnetic field. Heat Transf. 50(5), 4775-4787 (2021)

34. D. Gambo, T.S. Yusuf, S.A. Oluwagbemiga, J.D. Kozah and J.J. Gambo, Analysis of free convective hydromagnetic flow of heat generating/absorbing fluid in an annulus with isothermal and adiabatic boundaries, Partial Differ. Equ. Appl. Math., 4(100080) (2021)

35. B.K. Jha, D. Gambo, Hydrodynamic effect of slip boundaries and exponentially decaying/growing timedependent pressure gradient on Dean flow, J. Egyptian Math. Soc., 29(11) (2021)

36. B.K. Jha, D. Gambo, Theoretical investigation on the impact of an oscillating time-dependent pressure gradient on Dean flow in a porous annulus. Propulsion Power Res 10(3), 294-302 (2021) 
37. B.K. Jha, D. Gambo, Effect of an oscillating time-dependent pressure gradient on Dean flow: transient solution. Beni-Suef Univ. J. Basic Appl. Sci. 9(39), 1-9 (2020)

38. B.K. Jha, D. Gambo, Combined effects of suction/injection and exponentially decaying/growing timedependent pressure gradient on unsteady Dean flow: a semi-analytical approach. GEM Int. J. Geomath. 11(28), 1-22 (2020)

39. B.K. Jha, D. Gambo, Role of exponentially decaying/growing time-dependent pressure gradient on unsteady Dean flow: a Riemann-sum approximation approach. Arab J. Basic Appl. Sci. 28(1), 1 (2021)

40. T.S. Yusuf, D. Gambo, A.H. Olaife, Effect of heat source/sink on MHD start-up natural convective flow in an annulus with isothermal and isoflux boundaries. Arab J. Basic Appl. Sci. 27(1), 364-373 (2020)

41. S.I. Pai, Magnetogasdynamics and plasma dynamics (Springer, Berlin, 1962)

42. S. Tsangaris, D. Kondaxakis, N.W. Vlachakis, Exact solution of the Navier-Stokes equations for pulsating Dean flow in a channel with porous walls. Int. J. Eng. Sci. 44(11), 67-79 (2006)

43. D.Y. Tzou, Macro to Microscale Heat Transfer: The Lagging Behavior (Taylor and Francis, London, 1997) 